\title{
Lumpy Skin Disease: Global and Turkish Perspectives
}

\author{
Nuri Turan ${ }^{1}$, Aysun Yilmaz ${ }^{1}$, Bilge Kaan Tekelioglu² and Huseyin Yilmaz ${ }^{1 *}$ \\ ${ }^{1}$ Department of Virology, Veterinary Faculty, Turkey \\ ${ }^{2}$ Department of Virology, Ceyhan Veterinary Faculty, Turkey \\ *Corresponding author: Professor Huseyin Yilmaz, Department of Virology, Veterinary Faculty, Avcilar, Istanbul, Turkey
}

Submission: 眥 September 15, 2017; Published: 㭗 September 21, 2017

\begin{abstract}
Lumpy skin disease (LSD) is an economically important infection since the presence of the disease affects cattle health and export of cattle products. It is caused by capripoxvirus and shows characteristic skin lesions in infected cattle. The disease was first reported in Zambia, in 1929. It then spread to Africa, Middle East and recently to European countries like Greece and Bulgaria. The first Turkish outbreak of LSD was reported in 2013 in Kahramanmaras, Turkey. Until now, many cattle are affected and the disease spread to farms located in different parts of Turkey. After the first outbreak, rapid diagnostic methods have been used in order to identify disease outbreaks. Control and eradication programs have been applied by The Ministry of Food, Agriculture and Livestock of Republic of Turkey including contingency plan, culling and compulsory vaccination
\end{abstract}

Keywords: Lumpy skin disease; Cattle; Turkey

Abbreviations: LSD: Lumpy Skin Disease; LSDV: Lumpy Skin Disease Virus; IFAT: Indirect Fluorescin Antibody Test; VN: Virus Neutralization; GPCR: G-Protein-Coupled Chemokine Receptor; PCR: Protein-Coupled Chemokine Receptor

\section{Description and History of Lumpy Skin Disease (LSD)}

Lumpy skin disease (LSD) is a viral disease of cattle and buffaloes with characteristic skin lesions. Cattle health and trade are severely affected and therefore it is an emerging, economically important disease and potential treat to many countries [1-3]. The disease was first reported in Zambia in 1929 [2]. It was then spread to Africa, Middle East and recently to Caucasus and Balkan countries posing emerging risk to Europe and other countries (Figure 1) [2]. The first Turkish outbreak of LSD was reported in 2013 in Kahramanmaras, Turkey. Until now, many cattle were affected in different regions of Turkey $[4,5]$.

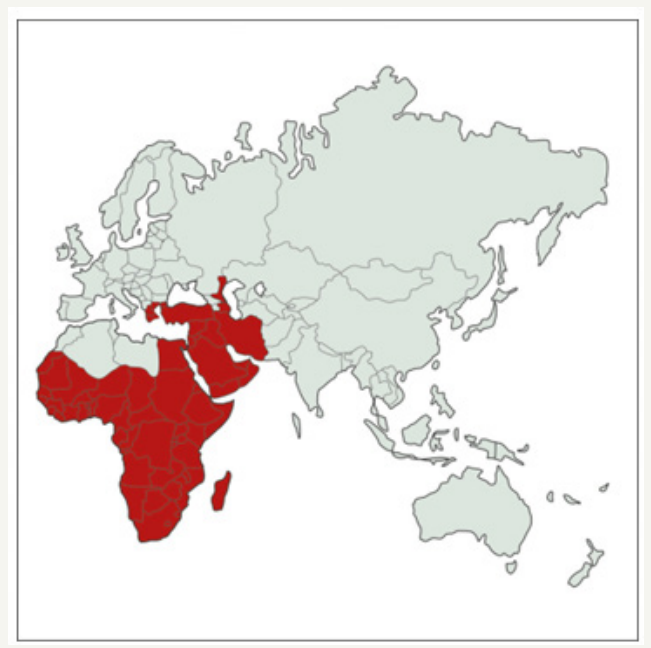

Figure 1: Geographical presence of lumpy skin disease, OIE data [2].

\section{Etiological agent}

Lumpy skin disease virus (LSDV) is a double-stranded DNA virus in the capripoxvirus genus of subfamily chordopoxvirinae within the family of poxviridae. It is an enveloped virus and has a genome size about $150 \mathrm{kbp}$ coding for 147 genes. The genome is conserved and has $97 \%$ of similarity with the goatpox and sheeppox viruses. Crossreactions between poxvirus species have been well established [6]. Therefore, these viruses cannot be distinguished by serological tests. They can only be differentiated by molecular analyses. Results of the molecular analyses have indicated that LSDV was found to be closer to goatpox than sheeppox. LSDV is considered to be 1 serotype called Neethling virus and used as reference strain [6]. The LSDV is very much resistant to environmental conditions. It may remain stabilized 18 and 35 days in the diried hide and skin lesions, respectively. It is sensitive to sunlight and lipid solvents. It can be inactivated by heating at $55^{\circ} \mathrm{C}$ for 2 hours and at $65^{\circ} \mathrm{C}$ for 30 minutes [7].

\section{Clinical signs}

LSDV cause characteristic skin lesions in infected cattle (Figure 2). Subclinical and clinical infections occur. At present, there is no carrier stage. Vectors can transmit the virus from the subclinical cattle without skin lesions [2]. Incubation period is 1 to 4 weeks and viraemia may last about 12 days [2]. Fever $\left(40{ }^{\circ} \mathrm{C}-41.5^{\circ} \mathrm{C}\right)$ and depression seen 1 to 4 weeks after the virus entry and may last for 4 to 14 days [8]. Secretions in the eye, mouth and nose may be increased and sometimes can be purulent. Lesions may occur in the mucosal sites. Lymph nodes are enlarged and after the fever 

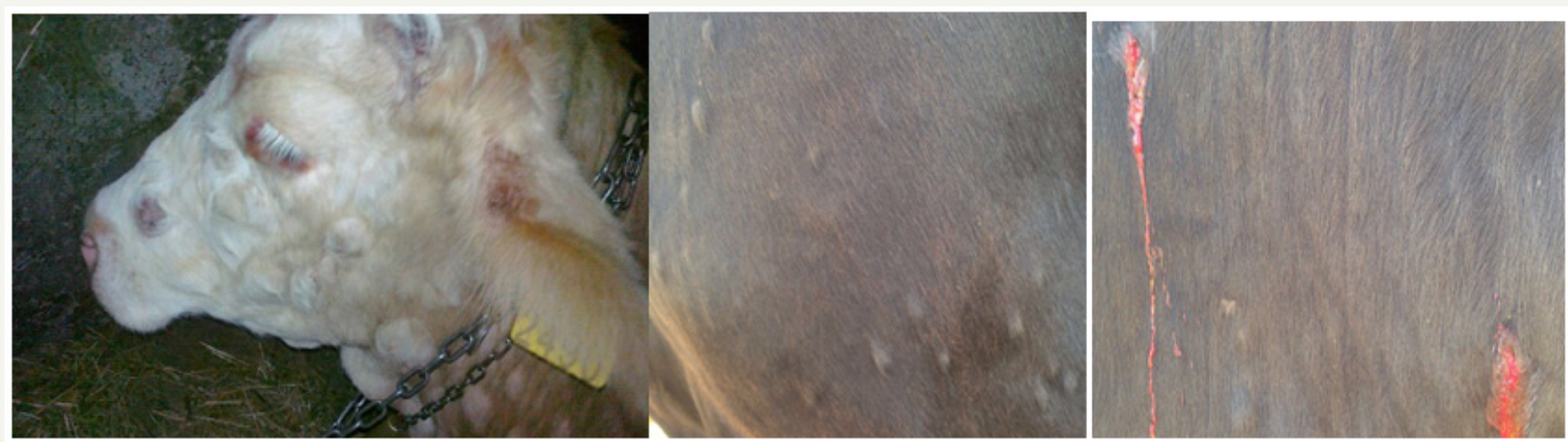

Figure 2: Skin lesions seen in cattle infected with LSDV (Original cases, Turkey). Right hand size indicates that some lesions can be erosive and pose great risk for spreading the virus by attracting flies.

In addition to characteristic skin lesions seen in infected cattle with LSDV, abortions, infertility, emaciation, decrease in milk and meat production, severe damage of hide have been observed causing significant economical losses as well as badly affected trade because of notification of the disease [9].

\section{Diagnosis}

Clinical appearance of the skin lesions makes suspicion of LSD. However, laboratory analyses are necessary for definitive diagnosis. Electron microscopy, virus isolation, serological and molecular tests have been used for the laboratory analyses of LSDV [10]. The main problem for LSD diagnosis is the differentiating infected from vaccinated animals as well as to detect subclinical animals. Serological tests are not sufficient to do that [11]. New diagnostic tests are necessary to differentiate vaccinated animals from infected as well as to detect subclinically infected animals.

LSDV can grove in cell cultures and embryonated chicken eggs. Lamb testis cells and bovine epidermal cells are generally used to culture LSDV with cytopathic effects in 7 days after inoculation by using the skin and blood of infected animals. It can also be adapted to VERO cells [12,13]. For serological analyses, agar gel immunediffusion, ELISA, indirect fluorescin antibody test (IFAT), virus neutralization (VN) and western immuneblotting are used [13]. Antibodies to LSDV can be detected by VN test after 21 days of infection [9]. Antibodies to LSDV were detected by ELISA in 56\% and $11.1 \%$ of the clinically infected and fevered cows, respectively [10]. The disadvantageous of serological tests is that vaccinated animals cannot be differentiated from infected animals as well as other poxviruses [9-11].

PCR and real time PCR have been used for molecular detection of LSDV in samples taken from skin lesions, blood, saliva, milk and semen [10,11,14-18]. Viral DNA can be detected in the skin lesions by PCR for 42 days [9] and 92 days [14] after experimental infection. Primers targeting g-protein-coupled chemokine receptor (GPCR), rpo30, p32 and ORF 132 gene are frequently used in PCR $[13,14]$. Prob based real time PCR has also been developed. A real time PCR has been assessed in order to detect and differentiate capripoxviruses [11]. Recently, a real time PCR was developed to differentiate vaccine and field strains [19].

\section{Epidemiology}

LSD is a disease of cattle (bos taurus and bos indicus) and buffaloes. However, it was shown that wild ruminants like Giraffe, Gazelle and Antelope are sensitive to LSDV infection [2]. Animal to animal transmission by close contact is minimal. Arthropod vectors play major role in transmission and spread of LSDV. Aedes aegypti mosquito for LSDV [20] and stomoxys calcitrans transmission for SPPV have been reported [21]. Horn flies, horse flies, midges also reported to transmit the virus. Novel evidence on the role of hard ticks has been found [22]. Virus can be transmitted by intradermal and intravenous injections. Therefore, iatrogenic transmission through injections and other applications have been occuring as well as human playing important role in spreading the virus [2].

Infected animals may harbour the virus in the skin lesions up to 39 days post infection [14]. LSDV has been found in cutaneous lesions, saliva, nasal discharge, milk, semen, muscles, and hides. Although, there is no report that LSDV transmitted through contact to body fluids but play important role in virus spread to the environment $[2,9]$. Dogs, cats as well as wild carnivores may play particular role in spreading the virus while carrying and eating the dead animals (personal comment). This point needs to be investigated. Subclinically and clinically affected animals are being transported to other parts of the country is another risk to spread the virus to different places [3].

Lumpy skin disease was first seen in Zambia in 1929 [2]. It was then occurred in Bostwana and Zimbabwe between 1943 and 1945 indicating the infectious behavior of the disease. In 1949, in South Africa, about 8.000 .000 cattle were affected by LSD [2,3,23,24]. After 1956, LSDV spread more or less to Africa continent as well as Madagascar and remained in Africa until 1986 [23]. It was then spread to Egypt in 1989 and nearly whole country had LSD cases and 1499 deaths were reported [3,10,23]. In 1989, LSD cases were reported in Israel indicating the virus spread outside the African continent. In both, Egypt and Israel, cattle were vaccinated 
with sheep poxvirus to control the infection. However, LSD cases remerged in Egypt and Israel in 2006 [2,3,10]. After these outbreaks and Syrian conflict, the LSD virus spread to Middle East countries and Turkey. First case of LSD was seen in Kahramanmaras, Turkey in 2013, August [5]. LSD cases have been reported now in Iran, Azerbaijan, Georgia and Balkan countries like Greece, Bulgaria and Macedonia posing high risk to bordering countries in Europe $[2,3,25,26]$ (Figure 3).

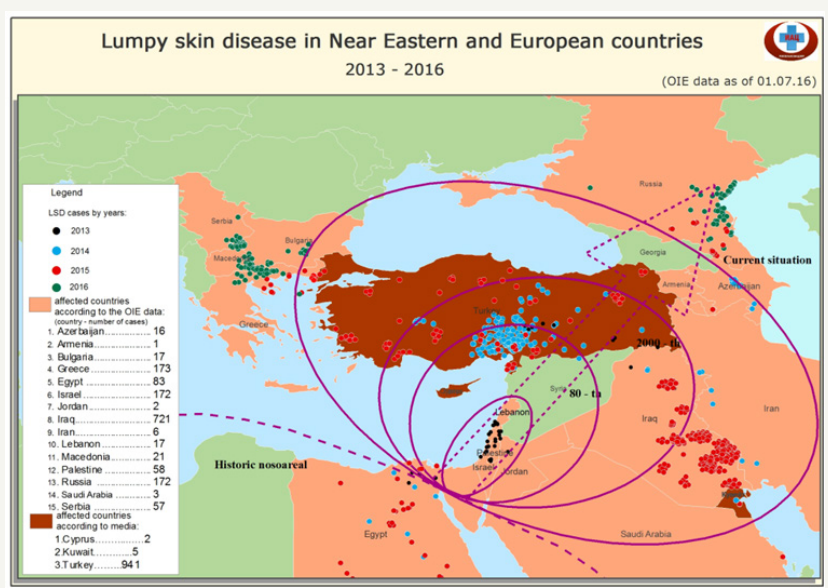

Figure 3: Lumpy skin disease in near eastern and European Countries 2013-2016. OIE data as of 01.07.2016 (from the report of European Commission, 2016

\section{Frequency of LSDV infections in Turkey}

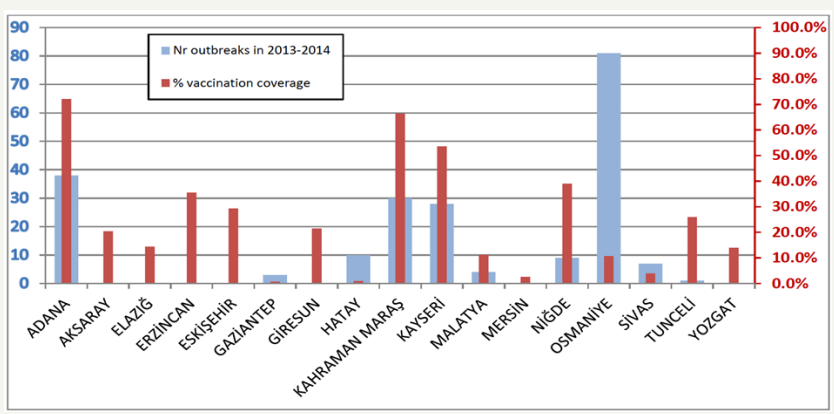

Figure 4: Number of outbreaks reported in 2013-2014 and vaccination coverage (RM-65 sheep pox strain) in Turkish provinces [30,31]. Tick bars (blue) show the number of out breaks in provinces. Thin bars (red) are the \% vaccine coverage.

LSD outbreaks in Turkey started in august 2013 [5], in Kahramanmaras after the outbreaks seen in Lebanon, Jordan and Israel in 2012 [1-3]. It was then spread quickly to neighboring localities and 18 outbreaks seen OIE data, [24,27,28] (Figure 4). In 2014, the number of outbreaks was 784 [29,30]. In 2015, LSD was spread all over the country occurring 510 outbreaks (OIE Data $[4,31])$. In 2016, the number of outbreaks and cases were decreased after the control measures taken by the Ministry of Food Agriculture and Livestock of Turkish Republic (OIE Data [4,31]). According to the data submitted to OIE, the highest morbidity and mortality rates in Turkey were $68 \%$ and $30 \%$, respectively $[5,29]$. The lethality rate was about $45 \%$. The morbidity and mortality rates were higher in 2013 but decreased after the infection was being notifiable and after vaccination started in 2014. The high number of cases was seen in vector season between July and November $[5,29]$.

\section{Control and Eradication}

Three control measures have been applied and scientific data indicated that these measures are found to be effective to control LSD [31]. These are:

I. Removal of infection by disinfection, vaccination, vector control, detection of subclinically infected animals, carcass disposal and culling infected animals.

II. Movement control by quarantine, animal movement control, zoning and control of imported animals and their products.

III. Networking and information by rising the awareness and education, epidemiological investigations, rapid diagnosis and rapid notification. Amongst these control measures, removal of infection (I) plays major role in controlling LSD [31].

Vaccination seems to be the most effective way to control LSD at present as well as disinfection, vector control, carcass disposal, culling infected animals, quarantine, animal movement control and rapid notification. In addition, there is need to produce new vaccines which are effective and safe.

\section{Control of LSD in Turkey}

Because of the antigenic similarities between the capripox viruses, sheep poxvirus has been used in immunization of cattle to control LSDV infections in cattle [32-34]. The compulsory vaccination of cattle started in Turkey in 2014 in high risk areas closer to the first outbreaks occurred. In this vaccination regime, 1 dose of sheep poxvirus vaccine was administered to a cattle. This vaccine was prepared from the local sheep poxvirus after 65 passages. This vaccine contains at least $\operatorname{TCID}_{50} 10^{2,5}$ viruses per dose and it is still currently in use against LSD in Turkey . In 2014, 1.590.757 cattle were vaccinated in the East and South East Anatolia region [35]. Animal movement and trade also restricted in those areas. Biosecurtiy measures, quarantine (30 days), culling and animal movement restriction were put in to force [4]. In 2015, all cattle were planned to be vaccinated in country wise. In this vaccination regime, 3 dose of sheep poxvirus vaccine was administered into cattle. About 8.125.947cattle were vaccinated in Turkey, in 2015 and 9.846 .506 cattle in 2016 [35]. The reason for the spread of LSD virus in 2015 might be due to the usage of 1 dose sheep poxvirus vaccine in cattle. This point indicates the importance of dose of vaccine to control LSD as well as vaccine strain used in vaccine. The sheep poxvirus vaccine can be used up to 10 doses higher in cattle. Therefore, recently, 5 dose of the sheep poxvirus vaccine has been recommended by the European Commision to be used in countries facing LSDV. More importantly, it is advisable that local strains of LSD should be used in vaccination. It has been suggested that a single vaccine can be used for all capripoxvirus infections because of antigenic similarities [32]. However, the findings by Gelaye \& others [34] indicated that local 
vaccines should be developed and host-specific vaccines should be used to control LSD outbreaks. In addition, from the experiences in Turkey, time of vaccination (before the vector season starting) and farmers support affect the success of vaccination.

\section{Conclusion}

LSD is a widespread disease and global treat for cattle industry. Vaccination seems to be the most effective way to control LSD in combination with biosecurity, vector control, quarantine and animal movement control. However, spread of vaccine strain to the environment and occurrence of possible mutations in the vaccine strain should be thought. Also there is always need to produce vaccine from local strains of LSDV as well as the optimal dose of vaccine used. The vaccine should be effective and safe.

\section{Experiences and suggestions}

i. Vaccination is the most important preventive measure along with biosecurity.

ii. Triple amount of attenuated sheep poxvirus seems to be working in vaccination but higher doses need to be evaluated.

iii. Rate of vaccination (up to $100 \%$ ) and vaccination time (before the vector activity) is important.

iv. A DIVA vaccine is urgently needed.

v. Clinical and field survey must be performed periodically.

vi. Early diagnosis, quarantine and culling are other control measures which should be applied urgently.

vii. Control of animal movement very important especially for sub clinically infected and in the incubation period animals.

viii. Vector control, in the field and even in the aircrafts and ships.

ix. New reservoirs and animals (dogs, cats and wild carnivores) possibly playing roll in spread of the virus needs to be investigated.

\section{References}

1. Abutarbush SM, Ababneh MM, Al Zoubi IG, Al Sheyab OM, Al Zoubi MG, et al. (2015) Lumpy skin disease in jordan: Disease emergence clinical signs, complications and preliminary-associated economic losses. Transbound Emerg Dis 62(5): 549-554.

2. Tuppurainen ESM, Venter EH, Shisler JL, Gari G, Mekonnen GA, et al. (2017) Review capripoxvirus diseases current status and opportunities for control. Transbound Emerg Dis 64(3): 729-745.

3. Alkhamis MA, Vander Waal K (2016) Spatial and temporal epidemiology of lumpy skin disease in the Middle East, 2012-2015. Front Vet Sci 3(3): 19.

4. General Directorate of Food and Control, Ministry of Food, Agriculture and Livestock of Republic of Turkey.

5. The World Organisation for Animal Health (OIE). Lumpy skin disease, Turkey.

6. Tulman ER, Afonso CL, Lu Z, Zsak L, Sur JH, et al. (2002) The genomes of sheeppox and goatpox viruses. JVI 76(12): 6054-6061.

7. OIE (2017) Technical disease cards.

8. Kumar SM (2011) An outbreak of lumpy skin disease in a holstein dairy herd in oman. A Clinical Report Asian J Anim Vet Adv 6: 851-859.
9. Babiuk S, Bowden TR, Parkyn G, Dalman B, Manning L, et al. (2008) Quantification of lumpy skin disease virus following experimental infection in cattle. Transbound Emerg Dis 55(7): 299-307.

10.Awad WS, Ibrahim AK, Mahran K, Fararh KM, Moniem MIA (2010) Evaluation of different diagnostic methods for diag-nosis of lumpy skin disease in cows. Trop Anim Health Prod 42(4): 777-783.

11.Lamien CE, Lelenta M, Goger W, Silber R, Tuppurainen E, et al (2011) Real time PCR method for simultaneous detection, quantitation and differentiation of capripoxviruses. J Virol Methods 171(1): 134-140.

12. House JA, Wilson TM, El Nakashly S, Karim IA, Ismail I, et al. (1990) The isolation of lumpy skin disease virus and bovine herpesvirus-4 from cattle in Egypt. J Vet Diagn Invest 2(2): 111-115.

13.OIE (2010) Manual of diagnostic tests and vaccines for terrestrial animals. Chapter 2.4.14. Lumpy skin disease.

14.Tuppurainen ES, Venter EH, Coetzer JA (2005) The detection of lumpy skin disease virus in samples of experimentally infected cattle using different diagnostic techniques. Onders-Tepoort J Vet Res 72: 153-164.

15. Gelaye E, Lamien CE, Silber R, Tuppura-Inen ES, Grabherr R, et al. (2013) Development of a cost-effective method for capri-poxvirus genotyping using snapback primer and dsdna intercalating dye. Plos One 8(10): e75971.

16. Ozgunluk I, Yumuşak N, Un H, Yilmaz R, Cablar M (2014) Lumpy skin disease (LSD) olgusunun molekuler ve histopatolojik tanisi XI. Veteriner hekimleri mikrobiyoloji kongresi (Uluslararasi katilimli) Sayfa: 80-81.

17.Gurcay M, Sait A, Parmaksiz A, Kilic A (2015) Turkiye de lumpy skin disease virus enfek-siyonunun klinik bulgular ve pcr yontemi ile saptanmasi. Kafkas Univ Vet Fak Derg 21(3): 417-420.

18. Tageldin MH, Wallace DB, Gerdes GH, Putterill JF, Greyling RR, et al. (2014) Lumpy skin disease of cattle. An emerging problem in the sultanate of oman. Trop Anim Health Prod 46(1): 241-246.

19. Menasherow S, Erster O, Rubinstein-Giuni M, Kovtunenko A, Eyngor E, et al. (2016) A High-Resolution Melting (HRM) assay for the differentiation between Israeli field and neethling vaccine lumpy skin disease viruses. J Virol Methods 232:12-15.

20.Chihota CM, Rennie LF, Kitching RP, Mellor PS (2011) Mechanical transmission of lumpy skin disease virus by aedes aegypti (Diptera: Culicidae). Epidemiol Infect 126(2): 317-321.

21. Kitching RP, Hammond JM (1986) Black studies On The Major Common Precipitating Antigen Of Capripoxvirus. J Gen. Virol 67 pp.139-148.

22.Tuppurainen ES, Stoltsz WH, Troskie M, Wallace DB, Oura CA, et al. (2011) A potential role for ixodid (hard) tick vectors in the transmission of lumpy skin disease virus in cattle. Transbound Emerg Dis 58: 93-104.

23. Davies FG (1991) Lumpy skin disease an african capripox virus disease of cattle. Br Vet J 147(6): 489-503.

24.Oner EB, Yesilbag K (2015) Lumpy skin disease turkiye de ilk salgina ilskin bazi epidemiyolojik veriler. Uludag Univ J. Fac Vet Med 34, 1(2): 41-52.

25. Zeynalova S, Asadov K, Guliyev F,Vatani M, Aliyev V (2016) Epizootology and molecular diagnosis of lumpy skin disease among livestock in azerbaijan. Front Microbiol 7: 1022.

26. Agianniotaki EI, Tasioudi KE, Chaintoutis SC, Iliadou P, ManganaVougiouka, et al. (2017) Lumpy skin disease outbreaks in greece during 2015-16, implementation of emergency immunization and genetic differentiation between field isolates and vaccine virus strains. Vet Microbiol 201: 78-84.

27. Ozkanlar YE, Timurkan MO, Degirmencay S, Ulas N, Aydin H (2015) Lumpy skin disease outbreak in cattle and temporary skin lesion with zoonotic character in an owner (abstract). 11. Veteriner ic Hastaliklari Kongresi p: 251.

28.Sevik M, Dogan M (2017) Epidemiological and molecular studies on lumpy skin disease outbreaks in turkeyduring 2014-2015. Transbound Emerg Dis 64(4): 1268-1279. 
29. OIE (2014) Reporting history turkey.

30.EFSA (2015) Scientific Opinion. Scientific opinion on lumpy skin disease EFSA panel on Animal Health And Welfare (AHAW). EFSA Joiurnal 13(1): 398.

31.EFSA (2016) Strengthening regional cooperation in South East Europe and middle east for prevention and control of Lumpy Skin Disease (LSD).
32. Chihota CM, Rennie LF, Kitching RP, Mellor PS (2003) Attempted mechanical transmission of lumpy skin disease virus by biting insects. Med Vet Entomol 17: 294-300. 